\title{
Proximate determinants of fertility in Ethiopia: comparative analysis of the 2005 and 2011 DHS
}

\author{
Yishak Abraham Lailulo and A. Sathiya Susuman
}

\begin{abstract}
Fertility is one of the elements in population dynamics that makes a significant contribution towards changing population size and structure over time. In Ethiopia, for the last 10 years the total fertility rate (TFR) has declined slightly from 5.5 to 4.8 children in 2011. But, the TFR in urban areas has increased from 2.4 to 2.6 per 1000 live births. The Bongaarts model was applied to estimate the indices of the four main proximate determinants of fertility. Bongaarts defines the TFR of a population as a function of the total fecundity rate $(\mathrm{TF})$, index of marriage $\left(\mathrm{C}_{\mathrm{m}}\right)$, index of contraception $\left(\mathrm{C}_{\mathrm{c}}\right)$, index of postpartum infecundability $\left(\mathrm{C}_{\mathrm{i}}\right)$, and index of abortion $\left(\mathrm{C}_{\mathrm{a}}\right)$; this can be written as $\mathrm{TFR}=$ $\mathrm{C}_{\mathrm{m}} \times \mathrm{C}_{\mathrm{c}} \times \mathrm{C}_{\mathrm{i}} \times \mathrm{C}_{\mathrm{a}} \times \mathrm{TF}$. In 2005, the index of married women in urban areas was lower than rural, but it was unfortunately the same in urban and rural areas in 2011. For the last decade, the index of postpartum infecundability had a great fertility reduction effect compared with the contraception index and marriage index in rural Ethiopia. The lower the four indices of proximate determinants, the more fertility will be reduced. As such, the Ethiopian government, international non-governmental organizations and policymakers must pay attention to increase the prevalence of contraceptive use and educate society to fight against child marriage. Permanent contraceptive use, such as female sterilization, should be promoted; moreover, legal organizations and the community must work together to raise the legal age of marriage to 18 years.
\end{abstract}

\section{Introduction}

Ethiopia is the second most populous country among Sub-Saharan Africa countries, and in 2015 the population was estimated at 94.53 million (Adugna, 2014). According to the Ethiopian Demographic and Health Survey (EDHS) 2000, the total fertility rate (TFR) in Ethiopia was 5.5 children per woman; this rate declined to 5.4 in 2005 (Teller, 2011) and further to 4.8 in 2011 (CSA, 2012). Although showing a declining trend, like many African countries, Ethiopia's fertility rate is still high. The TFR in urban Ethiopia is estimated at 2.6, and in rural areas it is estimated at 5.4 (per 1000 live births), according to the 2011 EDHS. This variation may be attributed to differences in cultural, economic and health factors which influence the process of human reproduction. Determinants such as the value society gives to children, preferences relating to the sex of a child and family size, the social position and role of women in a society, economic needs and old age security schemes, and the frequency of sexually transmitted diseases affect fertility. Social organizations and cultural effects have an influence on the pace of family formation and 
childbirth (Falls, 2007). There are two factors that determine fertility: direct or proximate determinants, and indirect determinants or background factors (Davis and Blake, 1956). The background factors work through the proximate determinants to influence fertility; they do not influence fertility directly. The proximate determinants are behavioral mechanisms that act to reduce fertility. The principal characteristics of the proximate determinants are their direct influence on fertility. Indirect determinants are socioeconomic, cultural and environmental (e.g. education, labor, and urban residence)those elements that, if changed, would causally result in a change in overall fertility levels, all else being equal (Bongaarts, 1978; Bongaarts and Potter, 1983).

Marriage is the best known proximate determinant of fertility. Marriage is defined as the relatively stable union to which socially approved childbearing is limited in most societies (Bongaarts and Potter, 1983). The formation of marriage is usually associated with the beginning of childbirth. In societies where women marry at an early age, the beginning of childbirth is early and the period during which women bear children is relatively longer (Bongaarts and Potter, 1983). The age at which marriage occurs and the proportion of women who are married, accompanied by a low level of contraceptive use, determine the level of fertility in a society (Bongaarts et al., 1984; Hailemariam, 1992). Contraceptive use is also a proximate determinant of fertility. After postpartum amenorrhea, the risk of getting pregnant increases should the woman become sexually active and not use any form of contraception. A study in Kenya showed that the value of the index of contraception $\left(\mathrm{C}_{\mathrm{C}}\right)$ has declined from 0.81 to 0.72 between 1989 and 2003. This decline signals an increasing role of contraception in fertility reduction (Anyara and Hinde, 2006). Similar studies in Eastern and Southern Africa show that contraceptive prevalence rates for modern methods are above or close to $50 \%$ in only two countries (Zimbabwe and Mauritius) and between $25 \%$ and $40 \%$ in five countries, namely Madagascar, Malawi, Kenya, Rwanda and Zambia (Guengant and May, 2011). In the remaining countries, use of modern methods averaged between $10 \%$ and $20 \%$. In addition to marriage and contraceptive use, women's exposure to the risk of pregnancy is determined by postpartum behavior. Postpartum amenorrhea, which is largely determined by the duration and intensity of breastfeeding and postpartum abstinence, determines the length of postpartum insusceptibility. Postpartum insusceptibility has an influence in the reduction of fertility (Blanc and Grey, 2000).

Therefore, this study compares the relative effects of marriage patterns, contraceptive use, and postpartum insusceptibility to fertility using the Bongaart's Proximate Determinants on Fertility framework. In addition, the study examines the relative contribution of each index for the reduction of fertility.

Hypothesis 1: The increase in contraceptive method use will decrease total fertility rate.

Hypothesis 2: Rural residence index of postpartum infecundability $\left(\mathrm{C}_{\mathrm{i}}\right)$ will decrease in 2011. 


\section{Data and methods}

\section{Data}

The EDHS 2005 and 2011 were used. From the EDHS 2005, the total number of eligible women was 14,070 and the study sample was 8914 (married women). According to the EDHS 2011, there were 16,515 eligible women but the study sample used 9594 (married women).

\section{Methods}

The TFR of a population is a function of the total fecundity rate (TF), index of marriage $\left(\mathrm{C}_{\mathrm{m}}\right)$, index of contraception $\left(\mathrm{C}_{\mathrm{c}}\right)$, index of postpartum infecundability $\left(\mathrm{C}_{\mathrm{i}}\right)$ and index of abortion $\left(\mathrm{C}_{\mathrm{a}}\right)$; the model is expressed as (Bongaarts, 1978, 1982): model is expressed as (Bongaarts, 1978, 1982):

$$
\mathrm{TFR}=\mathrm{C}_{\mathrm{m}} \times \mathrm{C}_{\mathrm{c}} \times \mathrm{C}_{\mathrm{i}} \times \mathrm{C}_{\mathrm{a}} \times \mathrm{TF}
$$

where TFR is total fertility rate, TF is the total fecundity rate, and $\mathrm{C}_{\mathrm{m}}, \mathrm{C}_{\mathrm{c}}, \mathrm{C}_{\mathrm{i}}$ and $\mathrm{C}_{\mathrm{a}}$ are indices measuring the fertility inhibiting effect of marriage, contraception, postpartum infecundability and abortion, respectively. The value of each of these four indices ranges between $\mathrm{O}$ and 1 . The index takes the value $\mathrm{O}$ when the fertility inhibition of the given intermediate fertility variable is complete, and equal to 1 when there is no fertility inhibition effect. These indices are estimated as:

$$
\mathrm{C}_{\mathrm{m}}=\mathrm{TFR} / \mathrm{TMR} ; \text { where } \mathrm{TMR}=\text { total marital fertility rate. }
$$

$$
\mathrm{C}_{\mathrm{c}}=1-\alpha(\mathrm{u}, \mathrm{e})
$$

Here $\alpha$ is an adjustment for the couple having not using contraceptive method, Bongaarts (1978) estimated the constant as 1.08.

$\mathrm{u}=$ Average proportion of married women currently using contraception. $\mathrm{e}=$ Useeffectiveness of contraceptive methods.

$\mathrm{C}_{\mathrm{i}}=$ Birth interval in absence of breastfeeding/ Birth interval in presence of postpartum non-susceptible period caused due to breastfeeding.

$$
\begin{gathered}
\mathrm{C}_{\mathrm{i}}=\frac{20}{18.5+i}, \\
\mathrm{C}_{\mathrm{a}}=\mathrm{TFR} /\{\mathrm{TFR}+0.4(1+\mathrm{u}) \mathrm{TA}\}, \text { where TA is total abortion rate }
\end{gathered}
$$


Bongaarts (1978) recognized that a relationship exists between the three cumulative fertility rates:

TFR, total marital rate (TM) and total natural marital fertility rate (TN).

The basic relations between these indices and the cumulative fertility measures are:

$$
\text { Total marital rate }(\mathrm{TM})=\mathrm{C}_{\mathrm{c}} * \mathrm{C}_{\mathrm{a}} * \mathrm{TN} \text {; }
$$

Total natural marital fertility rate $(\mathrm{TN})=\mathrm{C}_{\mathrm{i}} * \mathrm{TF}$

\section{Operational definition}

Age-specific fertility rate

Age-specific fertility rate is the number of births per year per 1000 women of a specific age (group).

It is calculated as

\section{Number of births to}

$$
\begin{aligned}
& \frac{\text { women age a }}{\text { Number of women }} \times 1000 \text { (Hopkins Public Health, 2006). } \\
& \text { age a }
\end{aligned}
$$

\section{Total fertility rate}

The total fertility rate is the average number of children that would be born to a woman by the time she ended childbearing if she were to pass through all her childbearing years conforming to the age-specific fertility rates (ASFRs) of a given year. It is also defined as the sum of the ASFRs (5-year age groups between 15 and 49) for female residents of a specified geographic area (nation, state, county, etc.) during a specified time period (usually a calendar year) multiplied by 5 . Please note that this rate estimates the number of children a hypothetical cohort of 1000 females in the specified population would bear if they all went through their childbearing years experiencing the same age-specific birth rates for a specified time period (United Nations data, 2010; United Nations, department of Economic and Social Affairs, 2008). Calculation: 5( $\sum$ ASFR) /1000, where ASFR is each 5-year ASFR.

\section{Total fecundity rate}

Fecundity is the capacity to reproduce; fertility, on the other hand, is the actual reproductive performance. Total fecundity rate is equal to the total natural marital fertility rate in the absence of lactation (Bongaarts, 1978). 


\section{Results}

This section consists of two analysis findings; the first comprises the four main indices of fertility model, and second computes the inhibiting effect of the each four proximate determinants on fertility.

\section{Index of marriage}

The index of marriage, $\mathrm{C}_{\mathrm{m}}$, (i.e. exposure to reproductive risk), would equal 1 if all women at reproductive risk were married and $\mathrm{o}$ in the total absence of intercourse. It is the weighed (by

Table I. Estimated index of marriage by place of residence in Ethiopia $20 \mathrm{II}$.

\begin{tabular}{|c|c|c|c|}
\hline \multirow[t]{2}{*}{ Age group } & \multicolumn{3}{|l|}{ Urban } \\
\hline & $\mathrm{m}(\mathrm{a})$ & ASFR & $g(a)$ \\
\hline $15-19$ & 0.044 & 27 & 613.6364 \\
\hline $20-24$ & 0.191 & 123 & 643.9791 \\
\hline $25-29$ & 0.288 & 158 & 548.6111 \\
\hline $30-34$ & 0.189 & 101 & 534.3915 \\
\hline $35-39$ & 0.158 & 75 & 474.6835 \\
\hline $40-44$ & 0.078 & 21 & 269.2308 \\
\hline $45-49$ & 0.052 & 22 & 423.077 \\
\hline Total & & 527 & 3507.609 \\
\hline \multirow[t]{2}{*}{ Age group } & \multicolumn{3}{|l|}{ Rural } \\
\hline & $\mathrm{m}(\mathrm{a})$ & ASFR & $g(a)$ \\
\hline $15-19$ & 0.077 & 99 & $|285.7| 4$ \\
\hline $20-24$ & 0.176 & 236 & 1340.909 \\
\hline $25-29$ & 0.255 & 262 & $1027.45 \mid$ \\
\hline 30-34 & 0.175 & 218 & $1245.7 \mid 4$ \\
\hline $35-39$ & 0.159 & |7| & 1075.472 \\
\hline $40-44$ & 0.095 & 77 & 810.5263 \\
\hline $45-49$ & 0.063 & 29 & 460.3175 \\
\hline Total & & 1092 & 7246.104 \\
\hline
\end{tabular}

Source: Computed by the authors from 20II EDHS; m(a): age-specific proportion of currently married women; ASFR: age-specific fertility rate.

age-specific marital fertility rates) averages of the age-specific proportions of currently married women as follows:

$$
\mathrm{C}_{\mathrm{m}}=\frac{\sum m(a){ }^{*} g(a)}{\sum g(a)}
$$

Where $m(a)=$ age-specific proportion of currently married women and $g(a)=$ age-specific marital fertility rates. The index $\mathrm{C}_{\mathrm{m}}$ gives the proportion by which TFR is smaller than TM 
as the result of non-marriage; $\mathrm{C}_{\mathrm{m}}=\mathrm{O}$ if nobody is married and $\mathrm{C}_{\mathrm{m}}=1$ if all women are married during the entire reproductive period. The index of marriage is intended to express the reduction in fertility caused by women not being sexually active throughout their entire reproductive period. Table 1 presents the age-specific proportion of currently married women, age-specific marital fertility rates, and ASFRs of all women based on the types of place of residence.

$$
\begin{aligned}
& \text { Urban. ASFR(a) }=\mathrm{m}(\mathrm{a}) * \mathrm{~g}(\mathrm{a}), \sum \operatorname{ASFR}(a)=527, \mathrm{TFR}=2.635, \mathrm{~g}(\mathrm{a})=5 \frac{3202.812}{1000}=5(3.507) \\
& =17.54, \mathrm{Cm}=5 \frac{T F R}{g(a)}=5 \frac{2.635}{17.54}=0.75
\end{aligned}
$$

Thus, the urban index of marriage is 0.75

Therefore, from the relationship $\mathrm{TFR}=\mathrm{Cm}{ }^{*} \mathrm{TM}$, the $\mathbf{T M}=\mathbf{T F R} / \mathbf{C m}=\mathbf{2 . 6 3 5} / \mathbf{0 . 7 5}=$ 3.51.

Table 2. Estimated use of effectiveness by contraceptive method for developing countries.

\begin{tabular}{ll}
\hline Method & Estimated use-effectiveness \\
\hline Sterilization & 1.00 \\
IUD & 0.95 \\
Pill & 0.90 \\
Other & 0.70
\end{tabular}

Source: Bongaarts, 1982.

Rural. ASFR (a) $=\mathrm{m}(\mathrm{a}) * \mathrm{~g}(\mathrm{a}), \sum \operatorname{ASFR}(a)=1092, \mathrm{TFR}=5.46, \mathrm{~g}(\mathrm{a})=5 \frac{7246.104}{1000}=5(7.246)$ $=36.23, \mathrm{C}_{\mathrm{m}}=5 \frac{T F R}{g(a)}=5 \frac{5.46}{36.23}=5(0.15)=0.75$. Thus, the urban index of marriage is 0.75 .

Hence, $\mathbf{T M}=\mathbf{T F R} / \mathbf{C m}=\mathbf{5 . 4 6 / 0 . 7 5}=\mathbf{7 . 3 0}, \mathrm{TM}$ is the total marital fertility rate.

\section{Index of contraception}

Index of contraception, $\mathrm{C}_{\mathrm{c}}$, would equal 1 in the absence of contraceptive use (e.g. natural fertility populations) and $\mathrm{o}$ if all women at reproductive risk employed completely effective contraception. This index takes into account both the prevalence and useeffectiveness of contraceptive practices employed by those at reproductive risk, and is calculated by:

$$
\mathrm{C}_{\mathrm{c}}=1-1.08 \times \mathrm{e} \times \mathbf{u}, \text { where: }
$$

$\mathbf{u}$ is the average proportion of married women currently using contraception(including abstinence; male methods and sterilization) e is the average contraceptive effectiveness; $\mathbf{1 . 0 8}$ is a sterility correction factor. 
Since estimates of contraceptive effectiveness are problematic to obtain and thus not often available, the Table 2 shows the standard method-specific values (adapted from data from the Philippines) which are used in the calculation of average effectiveness levels in developing countries (Bongaarts, 1982).

The average use-effectiveness, $\mathbf{e}$, is estimated as the weighted average of the methodspecific use-effectiveness levels $\mathbf{e}(\mathbf{m})$, with the weights equal to the proportion of women using a given method $\mathrm{u}(\mathrm{m})$. Thus,

$$
\mathrm{e}=\frac{u(m) * e(m)}{e(m)} .
$$

Urban

$$
\begin{aligned}
& \mathrm{e}=\frac{u(m) * e(m)}{e(m)}=\frac{0.46791}{0.493}=0.95, \mathrm{u}=\sum u(m)=0.95 . \text { Thus, } \\
& \mathrm{C}_{\mathrm{c}}=1-1.08 * \mathrm{u} * \mathrm{e}=1-0.506=0.5
\end{aligned}
$$

Rural

$$
\begin{aligned}
& e=\frac{u(m) * e(m)}{u(m)}=\frac{0.21114}{0.224}=0.94, \mathrm{u}=\sum u(m)=0.109 . \text { Thus, } \\
& \mathrm{C}_{\mathrm{c}}=1-1.08 * \mathrm{u} * \mathrm{e}=1-0.227=0.77
\end{aligned}
$$


Table 3. Estimating the index of contraception (20II EDHS).

\begin{tabular}{llll}
\hline Contraceptive use & Urban & & \\
\cline { 2 - 3 } & $\mathrm{u}(\mathrm{m})$ & $\mathrm{e}(\mathrm{m})$ & $\mathrm{u}(\mathrm{m}) * \mathrm{e}(\mathrm{m})$ \\
\hline Sterilization & 0.015 & $\mathrm{I} .00$ & 0.015 \\
Injection & 0.354 & 0.99 & 0.35046 \\
IUD & 0.009 & 0.95 & 0.00855 \\
Pill & 0.067 & 0.90 & 0.0603 \\
Other(condom and implant) & 0.048 & 0.70 & 0.0336 \\
Total & $\mathbf{0 . 4 9 3}$ & & $\mathbf{0 . 4 6 7 9 1}$ \\
\hline Contraceptive use & $\mathrm{Rural}$ & $\mathrm{u}(\mathrm{m}) * \mathrm{e}(\mathrm{m})$ \\
\cline { 2 - 4 } & $\mathrm{u}(\mathrm{m})$ & $\mathrm{e}(\mathrm{m})$ & 0.002 \\
\hline Sterilization & 0.002 & $\mathrm{I} .00$ & 0.17424 \\
Injection & 0.176 & 0.99 & 0.0019 \\
IUD & 0.002 & 0.95 & 0.0099 \\
Pill & $0.01 \mathrm{I}$ & 0.90 & $0.023 \mathrm{I}$ \\
Other(condom and implant) & 0.033 & 0.70 & $\mathbf{0 . 2}$ III4 \\
Total & $\mathbf{0 . 2 2 4}$ & & \\
\hline
\end{tabular}

Source: computed from 20I I EDHS. CU: Contraceptive use; $\mathrm{u}(\mathrm{m})$ : weighted the proportion of women using a given method; e(m): the weighted average of the method-specific use-effectiveness levels.

From the relationship $\mathrm{TM}=\mathrm{C}_{\mathrm{c}}{ }^{*} \mathrm{TNM}, \mathrm{TNM}=\mathrm{TM} / \mathrm{C}_{\mathrm{c}}$, where $\mathrm{TNM}$ is total natural marital fertility rate TNM (urban) $=3.51 / 0.5=7.02$. In addition to this, $\mathrm{TNM}$ (rural) $=$ $7 \cdot 30 / 0.77=9.50$

Table 3 presents the average use of contraceptive effectiveness (e) for urban 0.95 and rural 0.94. Comparative results of index of contraception $\left(\mathrm{C}_{\mathrm{c}}\right)$ for urban 7.02 and rural 9.40.TNM equals to TM in the absence of contraception and induced abortion.

From the relationship $\mathrm{TNM}=\mathrm{C}_{\mathrm{i}}$ * $\mathrm{TF}$; where $\mathrm{TF}$ is fecundity rate Urban, $\mathrm{TF}=\mathrm{TNM} / \mathrm{C}_{\mathrm{i}}=$ $7.02 / 0.56=12.54$ and Rural, $\mathrm{TF}=\mathrm{TNM} / \mathrm{C}_{\mathrm{i}}=9.50 / 0.55=17.30$ As we have shown in Table 3, both sterilization and IUD contraceptive method use were very low compared with other modern contraceptive use such as injection, pill and condom.

\section{Index of postpartum infecundability}

The index of postpartum infecundability, $\mathrm{C}_{\mathrm{i}}$, would equal 1 in the absence of postpartum amenorrhea (and postpartum abstinence) and $\mathrm{o}$ if the duration of postpartum infecundability were to continue indefinitely. An estimate of the index of postpartum infecundability is calculated as follows:

$$
\mathrm{C}_{\mathrm{i}}=\frac{20}{(18.5+i)}
$$

, where $i=$ average duration of postpartum infecundability caused by breast feeding 
(lactation amenorrhea) and/or and postpartum abstinence

$$
\mathrm{i}=1.753 * e^{0.1396^{*} B-0.001872 * B^{2}}:
$$

, where, $B$ is the duration of breast feeding.

Breast feeding duration, Urban $=24.3$ and Rural $=25.3$ (EDHS, 2011). Substituting the values in the place of $B$ we obtain the postpartum infecundability (i) of Urban $=17.26$ and Rural $=18.08$

$$
\text { Urban, } \mathrm{C}_{\mathrm{i}}=\frac{20}{18.5+17.26}=0.56 \text {, Rural, } \mathrm{C}_{\mathrm{i}}=\frac{20}{18.5+18.08}=0.55
$$

\section{Index of induced abortion}

The index of induced abortion, $\mathrm{Ca}$, would equal 1 in the absence of induced abortion and $\mathrm{o}$ if all pregnancies were interrupted by induced abortion. The index is calculated as follows:

$$
\mathrm{C}_{\mathrm{a}}=\frac{T F R}{T F R+0.4(1+u) * T A},
$$

Where $T F R=$ an estimate of the total fertility rate, $T A=$ total abortion rate, equal to the average number of induced abortions per women at the end of the reproduction period if induced abortion rates remain at prevailing levels throughout the reproductive period, and $u=$ proportion women using contraception.

In Ethiopia, induced abortion was difficult to establish as the data were not well recorded and were minimally available. Furthermore, the quality of data did not permit a valid estimate of TA; the index of induced abortion is taken to be 1 in both urban and rural residence of women in 2005 and 2011.

\section{Estimation of total fertility}

The total fertility rate is estimated from the indices according to the Bongaarts model:

$$
\mathrm{TFR}=15.3 \times \mathrm{C}_{\mathrm{m}} \times \mathrm{C}_{\mathrm{c}} \times \mathrm{C}_{\mathrm{a}} \times \mathrm{C}_{\mathrm{i}}
$$

The TF values of most populations fall within the range of 13 to 17 births per woman, with an average of $15 \cdot 3$.

The same procedure was performed to find the four main indices for proximate determinants in 2005. The computed results are shown below in Table 4. 
In 2005, $\mathrm{C}$ had the lowest value of all the indices of fertility in both urban and rural areas, with 0.55 and 0.58 , respectively. The corresponding value for TF in both urban and rural areas was 13.2 and 18.2 in 2005. In 2011, $C_{c}$ had the lowest value of all the indices of fertility in urban areas with a value of 0.50 , but the $\mathrm{C}_{\mathrm{i}}$ for rural women had a value of 0.55 .

The relative contribution accounted for by each proximate fertility determinants by birth per women

The Table 5 exhibits the magnitude of the total inhibiting effect being accounted by each proximate fertility determinant at two points in time. The differences between the TF and the estimated TFR are attributed as the result of the inhibiting effect of each determinant. The total inhibiting effect is prorated by the proportion of the logarithm of each index to the sum of logarithm of all indices (Wang et al., 1987). 
Table 4. Estimates of four important proximate determinants and the cumulative fertility rates in 2005 and $20 \mathrm{II}$.

\begin{tabular}{|c|c|c|c|c|}
\hline \multirow[t]{2}{*}{ Index estimate and fertility } & \multicolumn{2}{|c|}{ EDHS 2005} & \multicolumn{2}{|c|}{ EDHS 20II } \\
\hline & Urban & Rural & Urban & Rural \\
\hline$C_{m}$, index of married & 0.58 & 0.64 & 0.75 & 0.75 \\
\hline$C_{i}$, index of postpartum infecundability & 0.55 & 0.58 & 0.56 & 0.55 \\
\hline $\mathrm{C}_{c}$, contraception index & 0.57 & 0.89 & 0.50 & 0.77 \\
\hline $\mathrm{C}_{\mathrm{a}}$, index of induced abortion & 1.00 & 1.00 & 1.00 & 1.00 \\
\hline TM, total marital fertility rate & 4.14 & 9.40 & 3.51 & 7.30 \\
\hline TNM, total natural fertility rate & 7.26 & 10.56 & 7.02 & 9.50 \\
\hline TF, total fecundity & 13.2 & 18.20 & 12.54 & 17.30 \\
\hline TFR model & 2.78 & 5.05 & 3.21 & 5.01 \\
\hline TFR, total fertility rate from report & 2.4 & 6.00 & 2.63 & 5.46 \\
\hline
\end{tabular}

Source: Computed by the authors from 2005 and 201 I EDHS.

Table 5. Total inhibiting effects accounted for by each proximate fertility determinant in rural and urban women of Ethiopia in both 2005 and 2011.

\begin{tabular}{|c|c|c|c|c|}
\hline \multicolumn{5}{|l|}{ Fertility-inhibiting effects (EDHS 2005) } \\
\hline \multirow[t]{2}{*}{ Proximate determinants } & \multicolumn{2}{|c|}{ (Birth per women) } & \multicolumn{2}{|l|}{$\%$} \\
\hline & Urban & Rural & Urban & Rural \\
\hline$C_{m}$, proportion marriage & 3.45 & 4.70 & 32.00 & 40.30 \\
\hline $\mathrm{C}_{c}$, index of Contraception & 3.56 & 1.22 & 33.00 & 10.50 \\
\hline $\mathrm{C}_{\mathrm{i}}$, index of postpartum infecundity & 3.80 & 5.73 & 35.00 & 49.20 \\
\hline Total: TF-TFR (estimated) & 10.81 & 11.65 & 100.00 & 100.00 \\
\hline \multicolumn{5}{|c|}{ Fertility-inhibiting effects (EDHS 20II) } \\
\hline$C_{m}$, proportion marriage & 0.81 & 3.00 & 18.43 & 25.08 \\
\hline $\mathrm{C}_{\mathrm{c}}$, index of Contraception & 1.95 & 2.70 & 44.41 & 22.80 \\
\hline$C_{i}$, index of postpartum infecundability & 1.63 & 6.17 & 37.15 & 52.12 \\
\hline Total: TF-TFR (estimated) & 4.40 & 11.87 & 100.00 & 100.00 \\
\hline
\end{tabular}

Source: Computed by the authors from 2005 and 201 I EDHS.

\section{Inhibiting effect of each index by place of residence in 2005}

Urban. The fertility inhibiting effect of marriage is obtained as:

$$
\begin{aligned}
& [\text { TF-TFR (estimated })] \times \log \mathrm{C}_{\mathrm{m}} /\left(\log \mathrm{C}_{\mathrm{m}}+\log \mathrm{C}_{\mathrm{c}}+\log \mathrm{C}_{\mathrm{a}}+\log \mathrm{C}_{\mathrm{i}}\right) . \\
& =(13.2-2.4) * \frac{\log 0.58}{\log 0.58+\log 0.57+\log 0.55}=3.45
\end{aligned}
$$

The fertility inhibiting effect of contraception is obtained as: 


$$
\begin{aligned}
& {[\text { TF-TFR }(\text { estimated })] \times \log \mathrm{C}_{\mathrm{c}} /\left(\log \mathrm{C}_{\mathrm{m}}+\log \mathrm{C}_{\mathrm{c}}+\log \mathrm{C}_{\mathrm{i}}\right) .} \\
& =(13.2-2.4) * \frac{\log 0.57}{\log 0.58+\log 0.57+\log 0.55}=3.56
\end{aligned}
$$

The fertility inhibiting effect of lactational infecundability is obtained as:

$$
\begin{aligned}
& {[\text { TF-TFR (estimated) }] \times \log \mathrm{C}_{\mathrm{i}} /\left(\log \mathrm{C}_{\mathrm{m}}+\log \mathrm{C}_{\mathrm{c}}+\log \mathrm{C}_{\mathrm{i}}\right) .} \\
& =(13.2-2.4) * \frac{\log 0.55}{\log 0.58+\log 0.57+\log 0.55}=3.80
\end{aligned}
$$

Rural. The fertility inhibiting effect of marriage is obtained as:

$$
\begin{aligned}
& [\text { TF-TFR (estimated })] \times \log \mathrm{C}_{\mathrm{m}} /\left(\log \mathrm{C}_{\mathrm{m}}+\log \mathrm{C}_{\mathrm{c}}+\log \mathrm{C}_{\mathrm{i}}\right) . \\
& =(18.20-6.00) * \frac{\log 0.64}{\log 0.64+\log 0.89+\log 0.55}=4.70
\end{aligned}
$$

The fertility inhibiting effect of contraception is obtained as:

$$
\begin{aligned}
& {[\text { TF-TFR (estimated) }] \times \log \mathrm{C}_{\mathrm{c}} /\left(\log \mathrm{C}_{\mathrm{m}}+\log \mathrm{C}_{\mathrm{c}}+\log \mathrm{C}_{\mathrm{i}}\right) .} \\
& =(18.20-6.00) * \frac{\log 0.89}{\log 0.64+\log 0.89+\log 0.55}=1.22
\end{aligned}
$$

The fertility inhibiting effect of lactational infecundability is obtained as:

$$
\begin{aligned}
& [\text { TF-TFR (estimated })] \times \log \mathrm{C}_{\mathrm{i}} /\left(\log \mathrm{C}_{\mathrm{m}}+\log \mathrm{C}_{\mathrm{c}}+\log \mathrm{C}_{\mathrm{i}}\right) . \\
& =(18.20-6.00) * \frac{\log 0.58}{\log 0.64+\log 0.89+\log 0.55}=5.73
\end{aligned}
$$

\section{Inhibiting effect of each index by place of residence in 2011}

Urban. The fertility inhibiting effect of marriage is obtained as

$$
\begin{aligned}
& {[\text { TF-TFR }(\text { estimated })] \times \log \mathrm{C}_{\mathrm{m}} /\left(\log \mathrm{C}_{\mathrm{m}}+\log \mathrm{C}_{\mathrm{c}}+\log \mathrm{C}_{\mathrm{a}}+\log \mathrm{C}_{\mathrm{i}}\right) .} \\
& =(7.02-2.64) * \frac{\log 0.75}{\log 0.75+\log 0.50+\log 1+\log 0.56}=0.81
\end{aligned}
$$


The fertility inhibiting effect of contraception is obtained as

$$
\begin{aligned}
& [\text { TF-TFR (estimated })] \times \log \mathrm{C}_{\mathrm{c}} /\left(\log \mathrm{C}_{\mathrm{m}}+\log \mathrm{C}_{\mathrm{c}}+\log \mathrm{C}_{\mathrm{a}}+\log \mathrm{C}_{\mathrm{i}}\right) . \\
& =(7.02-2.64) * \frac{\log 0.50}{\log 0.75+\log 0.50+\log 1+\log 0.56}=1.95
\end{aligned}
$$

The fertility inhibiting effect of lactational infecundability is obtained as

$$
\begin{aligned}
& [\text { TF-TFR (estimated })] \times \log \mathrm{C}_{\mathrm{i}} /\left(\log \mathrm{C}_{\mathrm{m}}+\log \mathrm{C}_{\mathrm{c}}+\log \mathrm{C}_{\mathrm{a}}+\log \mathrm{C}_{\mathrm{i}}\right) . \\
& =(7.02-2.64) * \frac{\log 0.56}{\log 0.75+\log 0.50+\log 1+\log 0.56}=1.63
\end{aligned}
$$

Rural. The fertility inhibiting effect of marriage is obtained as

$$
\begin{aligned}
& {[\text { TF-TFR (estimated) }] \times \log \mathrm{C}_{\mathrm{m}} /\left(\log \mathrm{C}_{\mathrm{m}}+\log \mathrm{C}_{\mathrm{c}}+\log \mathrm{C}_{\mathrm{a}}+\log \mathrm{C}_{\mathrm{i}}\right) .} \\
& =[17.30-5.46] * \frac{\log 0.75}{\log 0.75+\log 0.77+\log 0.55+\log 1}=3.00
\end{aligned}
$$

The fertility inhibiting effect of contraception is obtained as

$$
\begin{aligned}
& [\text { TF-TFR (estimated })] \times \log \mathrm{C}_{\mathrm{c}} /\left(\log \mathrm{C}_{\mathrm{m}}+\log \mathrm{C}_{\mathrm{c}}+\log \mathrm{C}_{\mathrm{a}}+\log \mathrm{C}_{\mathrm{i}}\right) . \\
& =[17.30-5.46] * \frac{\log 0.77}{\log 0.75+\log 0.77+\log 1+\log 0.55}=2.70
\end{aligned}
$$

The fertility inhibiting effect of lactational infecundability is obtained as

$$
\begin{aligned}
& [\text { TF-TFR (estimated })] \times \log \mathrm{C}_{\mathrm{i}} /\left(\log \mathrm{C}_{\mathrm{m}}+\log \mathrm{C}_{\mathrm{c}}+\log \mathrm{C}_{\mathrm{a}}+\log \mathrm{C}_{\mathrm{i}}\right) . \\
& =[17.30-5.46] * \frac{\log 0.55}{\log 0.75+\log 0.77+\log 1+\log 0.55}=6.17
\end{aligned}
$$

\section{Relative contribution of each proximate determinant by percentage}

To measure the magnitude of the total inhibiting effect being accounted for by each of the proximate determinants of fertility is by simple decomposition of the difference between observed and potential fertility. To obtain the inhibiting effect of each proximate the basic Bongaarts model is transformed thus: $\ln (\mathrm{TF})-\ln (\mathrm{TFR})=\ln \left(\mathrm{C}_{\mathrm{i}}\right)+\ln \left(\mathrm{C}_{\mathrm{c}}\right)+$ $\ln \left(\mathrm{C}_{\mathrm{m}}\right)$, where $\ln$ denotes the natural $\log$ transformation. The proportional contribution 
of each determinant to the reduction of fertility from the TF to the TFR is given by the following formula:

$$
\begin{gathered}
\mathrm{C}_{\mathrm{c}}=\frac{100 \ln \left(C_{c}\right)}{\ln \left(C_{c}\right)+\ln \left(C_{i}\right)+\ln \left(C_{m}\right)+\ln \left(C_{a}\right)}\left(\% \text { reduction of } \mathrm{C}_{\mathrm{c}}\right) \\
\mathrm{C}_{\mathrm{m}}=\frac{100 \ln \left(C_{m}\right)}{\ln \left(C_{c}\right)+\ln \left(C_{i}\right)+\ln \left(C_{m}\right)+\ln \left(C_{a}\right)}\left(\% \text { reduction of } \mathrm{C}_{\mathrm{m}}\right) \\
\mathrm{C}_{\mathrm{i}}=\frac{100 \ln \left(C_{i}\right)}{\ln \left(C_{c}\right)+\ln \left(C_{i}\right)+\ln \left(C_{m}\right)+\ln \left(C_{a}\right)}\left(\% \text { reduction of } \mathrm{C}_{\mathrm{i}}\right) \\
\mathrm{C}_{\mathrm{a}}=\frac{100 \ln \left(C_{a}\right)}{\ln \left(C_{c}\right)+\ln \left(C_{i}\right)+\ln \left(C_{m}\right)+\ln \left(C_{a}\right)}\left(\% \text { reduction of } \mathrm{C}_{\mathrm{a}}\right)
\end{gathered}
$$

The percentage contributions of other determinants can be computed thus. This percentage standardizes the result (Odimegwu and Zerai, 1996). Using the formula below, the percentage reductions by the four proximate determinants are computed below.

Relative contribution of each index for the reduction of fertility by percentage between urban and rural in 2005

Urban

$$
\begin{aligned}
& \mathrm{C}_{\mathrm{m}}=\frac{100 \ln \left(C_{m}\right)}{\ln \left(C_{c}\right)+\ln \left(C_{i}\right)+\ln \left(C_{m}\right)+\ln \left(C_{a}\right)}=\frac{100 \ln 0.58}{\ln 0.57+\ln 0.55+\ln 0.58+\ln 1}=32 \\
& \mathrm{C}_{\mathrm{c}}=\frac{100 \ln \left(C_{c}\right)}{\ln \left(C_{c}\right)+\ln \left(C_{i}\right)+\ln \left(C_{m}\right)+\ln \left(C_{a}\right)}=\frac{100 \ln 0.57}{\ln 0.57+\ln 0.58+\ln 0.55+\ln 1}=33 \\
& \mathrm{C}_{\mathrm{i}}=\frac{100 \ln \left(C_{i}\right)}{\ln \left(C_{c}\right)+\ln \left(C_{i}\right)+\ln \left(C_{m}\right)+\ln \left(C_{a}\right)}=\frac{100 \ln 0.55}{\ln 0.57+\ln 0.58+\ln 0.55+\ln 1}=35
\end{aligned}
$$


Rural

$$
\begin{aligned}
& \mathrm{C}_{\mathrm{m}}=\frac{100 \ln \left(C_{m}\right)}{\ln \left(C_{c}\right)+\ln \left(C_{i}\right)+\ln \left(C_{m}\right)+\ln \left(C_{a}\right)}=\frac{100 \ln 0.64}{\ln 0.64+\ln 0.89+\ln 0.58+\ln 1}=40.30 \\
& \mathrm{C}_{\mathrm{c}}=\frac{100 \ln \left(C_{c}\right)}{\ln \left(C_{c}\right)+\ln \left(C_{i}\right)+\ln \left(C_{m}\right)+\ln \left(C_{a}\right)}=\frac{100 \ln 0.89}{\ln 0.89+\ln 0.58+\ln 0.64+\ln 1}=10.50 \\
& \mathrm{C}_{\mathrm{i}}=\frac{100 \ln \left(C_{i}\right)}{\ln \left(C_{c}\right)+\ln \left(C_{i}\right)+\ln \left(C_{m}\right)+\ln \left(C_{a}\right)}=\frac{100 \ln 0.58}{\ln 0.89+\ln 0.58+\ln 0.64+\ln 1}=49.20
\end{aligned}
$$

Relative contribution of each index for the reduction (inhibiting) of fertility by percentage between urban and rural in 2011

Urban

$$
\begin{aligned}
& \mathrm{C}_{\mathrm{m}}=\frac{100 \ln \left(C_{m}\right)}{\ln \left(C_{c}\right)+\ln \left(C_{i}\right)+\ln \left(C_{m}\right)+\ln \left(C_{a}\right)}=\frac{100 \ln 0.75}{\ln 0.50+\ln 0.56+\ln 0.75+\ln 1}=18.43 \\
& \mathrm{C}_{\mathrm{c}}=\frac{100 \ln \left(C_{c}\right)}{\ln \left(C_{c}\right)+\ln \left(C_{i}\right)+\ln \left(C_{m}\right)+\ln \left(C_{a}\right)}=\frac{100 \ln 0.50}{\ln 0.50+\ln 0.56+\ln 0.75+\ln 1}=44.41 \\
& \mathrm{C}_{\mathrm{i}}=\frac{100 \ln \left(C_{i}\right)}{\ln \left(C_{c}\right)+\ln \left(C_{i}\right)+\ln \left(C_{m}\right)+\ln \left(C_{a}\right)}=\frac{100 \ln 0.56}{\ln 0.50+\ln 0.56+\ln 0.75+\ln 1}=37.15
\end{aligned}
$$

Rural 


$$
\begin{gathered}
\mathrm{C}_{\mathrm{m}}=\frac{100 \ln \left(C_{m}\right)}{\ln \left(C_{c}\right)+\ln \left(C_{i}\right)+\ln \left(C_{m}\right)+\ln \left(C_{a}\right)}=\frac{100 \ln 0.75}{\ln 0.77+\ln 0.55+\ln 0.75+\ln 1}=25.08 \\
\mathrm{C}_{\mathrm{c}}=\frac{100 \ln \left(C_{c}\right)}{\ln \left(C_{c}\right)+\ln \left(C_{i}\right)+\ln \left(C_{m}\right)+\ln \left(C_{a}\right)}=\frac{100 \ln 0.77}{\ln 0.77+\ln 0.55+\ln 0.75+\ln 1}=22.80 \\
\mathrm{C}_{\mathrm{i}}=\frac{100 \ln \left(C_{i}\right)}{\ln \left(C_{c}\right)+\ln \left(C_{i}\right)+\ln \left(C_{m}\right)+\ln \left(C_{a}\right)}=\frac{100 \ln 0.55}{\ln 0.77+\ln 0.55+\ln 0.75+\ln 1}=52.12
\end{gathered}
$$

As we can see from Table 5, the indexes of marriage in urban and rural areas reflect a reduction of fertility of $32 \%$ and $40.30 \%$, respectively in 2005 . Instead of increasing, the inhibiting effect of the index of marriage in both urban and rural areas has declined from $32 \%$ to $18.43 \%$ and $40.30 \%$ to $25.08 \%$ in 2011 , respectively.

\section{Decomposition of change in TFR during the period 2005-2011}

The contribution made by each of the proximate determinants of fertility to an observed change in fertility between two points of time can be quantified by using the decomposition equation:

$$
\begin{gathered}
\operatorname{TFR}(2011) / \mathrm{TFR}(2005)=\mathrm{C}_{\mathrm{m}}(2011) / \mathrm{C}_{\mathrm{m}}(2005)+\mathrm{C}_{\mathrm{i}}(2011) / \mathrm{C}_{\mathrm{i}}(2005) \\
+\mathrm{C}_{\mathrm{a}}(2011) / \mathrm{C}_{\mathrm{a}}(2005)+\mathrm{C}_{\mathrm{c}}(2011) / \mathrm{C}_{\mathrm{c}}(2005)+\mathrm{TF}(2011) / \mathrm{TF}(2005) . \\
\mathrm{Pf}=\mathrm{Pm}+\mathrm{Pi}+\mathrm{Pa}+\mathrm{Pc}+\mathrm{Pt}+\mathrm{I}
\end{gathered}
$$

where Pf $=$ [TFR (2011)/TFR (2005) $]-1=$ Proportional change in TFR between 2005 and 2011.

$\mathrm{Pm}=\left[\mathrm{C}_{\mathrm{m}}(2011) / \mathrm{C}_{\mathrm{m}}(2005)\right]-1=$ Proportional change in TFR between 2005 and 2011 due to change in marriage. 
Table 6. Decomposition of change in TFR between 2005 and 201 I by place of residence.

\begin{tabular}{|c|c|c|c|c|}
\hline \multirow[t]{2}{*}{ Factor responsible for fertility change } & \multicolumn{2}{|c|}{$\begin{array}{l}\% \text { of change in } \\
\text { TFR }\end{array}$} & \multicolumn{2}{|c|}{$\begin{array}{l}\text { Distribution of \% of } \\
\text { change in TFR }\end{array}$} \\
\hline & Urban & Rural & Urban & Rural \\
\hline Proportion of Women marriage $(\mathrm{Pm})$ & 29.31 & 17.20 & 299.08 & -191.11 \\
\hline Contraception Practices $(\mathrm{Pc})$ & -12.28 & -13.48 & -125.30 & 149.78 \\
\hline $\begin{array}{l}\text { Duration of postpartum infecundability } \\
\text { (Pi) }\end{array}$ & 1.82 & -5.17 & 18.57 & 57.44 \\
\hline Other proximate determinants $(\mathrm{Pt})$ & -5.00 & 28.80 & -51.00 & -320 \\
\hline Interaction (I) & -4.05 & -36.35 & -41.33 & 403.89 \\
\hline Total & 9.80 & $-9.00 \%$ & 100.00 & 100.00 \\
\hline
\end{tabular}

Source: Computed by the authors from 2005 and 20II EDHS.

$\mathrm{Pc}=\left[\mathrm{C}_{\mathrm{c}}(2011) / \mathrm{C}_{\mathrm{c}}\right.$ (2005) $]-1=$ Proportional change in TFR between 2005 and 2011 due to change in contraception.

$\mathrm{Pi}=\left[\mathrm{C}_{\mathrm{i}}(2011) / \mathrm{C}_{\mathrm{i}}(2005)\right]-1=$ Proportional change in TFR between 2005 and 2011 due to change in postpartum infecundability.

$\mathrm{Pa}=\left[\mathrm{C}_{\mathrm{a}}(2011) / \mathrm{C}_{\mathrm{a}}(2005)\right]-1=$ Proportional change in TFR between 2005 and 2011 due to change in induced abortion.

$\mathrm{Pt}=[\mathrm{TF}(2011) / \mathrm{TF}$ (2005) $]-1=$ Proportional change in TFR between 2005 and 2011 due to change in total fecundity rate.

The interaction factor I can be easily obtained by subtracting the sum of $\mathrm{Pm}, \mathrm{Pi}, \mathrm{Pa}, \mathrm{Pc}$ and Pr from Pf. The decomposition equation simply yields the proportional change in TFR between two points of times, which equals the sum of the proportional change of the proximate determinants, and an interaction term.

The absolute change in TFR can be estimated by reusing the decomposition equation as [TFR (2011) - TFR (2005)] $\times$ TFR (2005), i.e. [TFR (2011) - TFR (2005)] = TFR (2005) $\times[\mathrm{Pm}+\mathrm{Pi}+\mathrm{Pa}+\mathrm{Pc}+\mathrm{Pr}+\mathrm{I}]$.

\section{A comparison of results between 2005 and 2011}

The two indices such as $\mathrm{C}_{\mathrm{c}}$ and $\mathrm{C}_{\mathrm{i}}$ have dropped in 2011 and $\mathrm{C}_{\mathrm{m}}$ has increased in both urban and rural residence. On the other, the percentage of fertility inhibiting effects for $\mathrm{C}_{\mathrm{c}}$ and $\mathrm{C}_{\mathrm{i}}$ in urban areas has increased from $33 \%$ to $44.41 \%$ and $35 \%$ to $37.15 \%$, respectively, in 2011. Likewise, the percentage of fertility inhibiting effects on $\mathrm{C}_{\mathrm{c}}$ and $\mathrm{C}_{\mathrm{i}}$ in rural areas has increased from $10.50 \%$ to $22.80 \%$ and $49.20 \%$ to $52.12 \%$, respectively, in 2011. 


\section{Discussion}

In 2005, the index of married women in urban areas was lower than in rural areas, with values of 0.58 and 0.64 rural, respectively. Whereas, in 2011, the index of proportions married was unfortunately the same in urban and rural areas with values for $\mathrm{C}_{\mathrm{m}}$ of 0.75 . This may be due to cultural factors in both urban and rural areas which contributed the same proportions. There was a considerable variation in the index of contraception between urban and rural areas; in 2005 the index of contraception was recorded by the higher inhibiting effect of fertility for urban women compared with rural women, whereas in 2011 the index of contraception was registered by the highest inhibiting effect of fertility for rural women than that of urban women. There was little variation in $\mathrm{C}_{\mathrm{i}}$, the index of postpartum infecundability. In both 2005 and 2011 the index of postpartum infecundability was recognized by greatest fertility reduction effect compared with the index of contraception and index of marriage in rural residence. In addition to this, rural women reported highest durations of breastfeeding. Postpartum abstinence produces a reduction in the natural fertility level, with TN varying from 9.50 among the rural (with the highest i) women to 7.02 among the urban (with the lowest i) in 2011.

Contraceptive use yields a reduction in the total marital fertility rate. Even though contraceptive use increased from 2005 to 2011 in urban areas, the TFR has increased from 2.4 to 2.6 in 2011. Thus, for Hypothesis 1-increasing contraceptive method use will decrease the total fertility rate-to be true it should be modified: increasing contraceptive method use will decrease TFR if other three indices of proximate determinants $\left(\mathrm{C}_{\mathrm{i}}, \mathrm{C}_{\mathrm{m}}\right.$ and $\left.\mathrm{C}_{\mathrm{a}}\right)$ are fixed or decreasing. On the other hand, Hypothesis 2 is accepted. Increasing contraceptive (decreasing $\mathrm{C}_{\mathrm{c}}$ ) use leads to further reduction of 1.95 births in urban areas and 2.70 births in rural areas in 2011; in 2005 contraceptive use was contributing towards the reduction of fertility with 3.56 births in urban areas and 1.22 births in rural areas. This combines the impact of all the proximate fertility variables. In 2011, fertility (estimated by the model) in rural women was closer to the actual value than that of urban women.

\section{Conclusion}

This paper has tried to explore the contribution of the four main proximate determinants to fertility differentials in Ethiopia between the periods of 2005 and 2011. The index of contraception $\left(\mathrm{C}_{\mathrm{c}}\right)$ for urban and rural has dropped from 0.57 to 0.50 and 0.89 to 0.77 , respectively, in 2011. Likewise, the index of postpartum infecundability for urban and rural areas has dropped slightly from 0.55 to 0.56 and from 0.58 and 0.55 , respectively, in 2011. But, index of marriage $\left(\mathrm{C}_{\mathrm{m}}\right)$ has increased for both urban and rural, 0.58 to 0.75 and 0.64 to 0.75 , respectively, in 2011. The lower the four indices of proximate determinants, the greater the reduction in fertility. The findings have shown that two index of proximate determinants, $\mathrm{C}_{\mathrm{c}}$ and $\mathrm{C}_{\mathrm{i}}$, have been improved in 2011. The index of marriage has not been improved, and this means that if more people in both urban and rural areas are getting married at an early age, the probability having children in their lifetime will be increased. We suggest that the Ethiopian government, international NGOs and policy-makers have to focus on increasing the prevalence of contraceptive 
use and on educating society in not allowing their children to marry at an early age. A new policy should be formulated to focus on women's contraceptive use and on teaching about the risks of child marriage.

\section{Funding}

The author(s) received no financial support for the research, authorship, and/or publication of this article. 


\section{References}

Adugna A (2014) ORG. Development and Cultural Change, 211-235. Available at: www.ethiodemographyandhealth.

Anyara EL and Hinde A (2006) Fertility transition in Kenya: A regional analysis of the proximate determinants. Southampton, UK: Southampton Statistical Sciences Research Institute, 55pp. (S3RI Applications and Policy Working Papers, Ao6/o3).

Blanc AK and Grey S (2000) Greater than Expected Fertility Decline in Ghana: An Examination of the Evidence. Calverton, Maryland: Macro International, MEASURE DHS+, 2000 August, 23pp.

Bongaarts J (1978) A framework for analyzing the proximate determinants of fertility. Population and Development Review 4(1): 105-132.

Bongaarts $J$ (1982) The fertility-inhibiting effects of the intermediate fertility variables. Studies in Family Planning 13(6-7): 179-189.

Bongaarts J and Potter RG (1983) Fertility, Biology, and Behavior: An Analysis of the Proximate Determinants. New York: Academic Press.

Bongaarts J, Frank O and Lesthaeghe R (1984) The proximate determinants of fertility in sub-Saharan Africa. Population and Development Review 10(3): 511-537.

CSA-Ethiopia ICF (2012) International: Ethiopia Demographic and Health Survey 2011. Central Statistical Agency of Ethiopia and ICF International Addis Ababa, Ethiopia and Calverton, Maryland, USA. Available at: http://www.measuredhscom/publications/publication-fr255-dhs-final-reports.cfm (accessed 25 June 2013).

Davis K and Blake J (1956) Social structure and fertility: An analytic framework. Economic Development and Cultural Change 4(4): 112-135.

Falls JA (2007) Population a Lively Introduction. Washington, DC: Population Reference Bureau.

Guengant JP and May JF (2011) Proximate determinants of fertility in sub-Saharan Africa and their possible use in fertility projections. United Nations, Department of Economic and Social Affairs, Population Division, Expert Paper, No. 2011/13. Available at: http://ocw.jhsph.edu/courses/PopulationChange/ PDFs/Lecture4.pdf

Hailemariam A (1992) An overview of the determinants of high fertility in Ethiopia. Ethiopian Journal of Development Research 14(2): 1-30.

Johns Hopkins Bloomberg School of Public Health (2006) Available at: http://www.un.org/esa/population/publications/WFD\%202008/WP_WFD_200

8/Data.html

Odimegwu CO and Zerai A (1996) Understanding the proximate determinants of fertility of a Nigerian ethnic group. Genus 52(3-4): 67-87. Available at: http://www.jstor.org/stable/29789250 (accessed 28 February 2012).

Teller C (Ed.) (2011) The Demographic Transition and Development in Africa. Springer Science+ Business Media BV.

United Nations, Department of Economic and Social Affairs, Population Division. World Fertility Data (2008) Available at: (http://www.un.org/esa/population/publications/WFD\%202008/WP_WFD_200 8/ Data.html) 
United Nations (2010) United Nations, Department of Economic and Social Affairs, Population Division, World Population Prospects: The 2010 Revision. New York, 2011 (accessed 3 January 2012).

Wang SX, Chen Y-D, Chen CHC, Rochat RW, Chow LP and Rider RV (1987) Proximate determinants of fertility and policy implications in Beijing. Studies in Family Planning 18(4): 222-228.

\section{Author biographies}

Yishak Abraham Lailulo is a doctoral research fellow in the Dept. of Statistics and Population Studies, University of the Western Cape, Cape Town, South Africa.

Professor A Sathiya Susuman is a Faculty member, University of the Western Cape, Dept. of Statistics and Population Studies, Cape Town, South Africa. His specific research area is fertility, mortality, gender, reproductive health and public health. 